\title{
Utilising shade to optimize UV exposure for vitamin D
}

\author{
D. J. Turnbull and A. V. Parisi \\ Centre for Rural and Remote Area Health, University of Southern Queensland, Toowoomba, Queensland 4350, Australia
}

Received: 29 November 2007 - Published in Atmos. Chem. Phys. Discuss.: 16 January 2008

Revised: 7 April 2008 - Accepted: 9 May 2008 - Published: 2 June 2008

\begin{abstract}
Numerous studies have stated that humans need to utilise full sun radiation, at certain times of the day, to assist the body in synthesising the required levels of vitamin $D_{3}$. The time needed to be spent in the full sun depends on a number of factors, for example, age, skin type, latitude, solar zenith angle. Current Australian guidelines suggest exposure to approximately $1 / 6$ to $1 / 3$ of a minimum erythemal dose (MED), depending on age, would be appropriate to provide adequate vitamin $\mathrm{D}_{3}$ levels. The aim of the study was to determine the exposure times to diffuse solar UV to receive exposures of 1/6 and 1/3 MED for a changing solar zenith angle in order to assess the possible role that diffuse UV (scattered radiation) may play in vitamin $\mathrm{D}_{3}$ effective $\mathrm{UV}$ exposures $\left(\mathrm{UV}_{\mathrm{D}_{3}}\right)$. Diffuse and global erythemal UV measurements were conducted at five minute intervals over a twelve month period for a solar zenith angle range of $4^{\circ}$ to $80^{\circ}$ at a latitude of $27.6^{\circ} \mathrm{S}$. For a diffuse UV exposure of $1 / 3 \mathrm{MED}$, solar zenith angles smaller than approximately $50^{\circ}$ can be utilised for exposure times of less than $10 \mathrm{~min}$. Spectral measurements showed that, for a solar zenith angle of $40^{\circ}$, the UVA $(315-400 \mathrm{~nm})$ in the diffuse component of the solar UV is reduced by approximately $62 \%$ compared to the UVA in the global UV, whereas $\mathrm{UV}_{\mathrm{D}_{3}}$ wavelengths are only reduced by approximately $43 \%$. At certain latitudes, diffuse UV under shade may play an important role in providing the human body with adequate levels of $\mathrm{UV}_{\mathrm{D}_{3}}(290-315 \mathrm{~nm})$ radiation without experiencing the high levels of UVA observed in full sun.
\end{abstract}

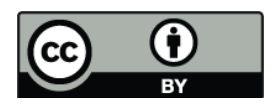

Correspondence to: D. J. Turnbull (turnbull@usq.edu.au)

\section{Introduction}

The health effects of solar UV radiation vary significantly, from initiating the synthesis of vitamin $\mathrm{D}_{3}$ to the severe degradation of the human body. Excessive solar UV radiation exposure led to the premature deaths of approximately 60000 people in the year 2000 (Lucas et al., 2006). It is well known that exposure to small amounts of UV radiation are beneficial for the human body and important in the production of vitamin $D_{3}$, whereas excessive exposure to sunlight is known to cause skin cancer, immune suppression, DNA damage, erythema and sun-related eye disorders (Baron et al., 2003; Glerup et al., 2000; Terenetskaya, 2000; Sliney, 2004; Setlow et al., 1993). Approximately $90-95 \%$ of our vita$\min \mathrm{D}_{3}$ requirement comes from exposure to the sun (Holick, 2004; Holick, 1998). The synthesis of pre-vitamin $D_{3}$ is initiated through exposure of human skin to terrestrial UV radiation from 290 to $315 \mathrm{~nm}$. The longer wavelength UV radiation (greater than $315 \mathrm{~nm}$ ) plays no part in the synthesis of pre-vitamin $\mathrm{D}_{3}$ in humans. Although, over exposure to UV wavelengths is known to cause damage, vitamin $\mathrm{D}_{3}$ synthesis occurs at doses far below those needed for erythema to arise (Webb, 1993). Small amounts of vitamin $D_{3}$ can also be obtained from some foods, for example oily fish and eggs or by fortifying foods with vitamin $\mathrm{D}_{3}$. It has been shown that the vitamin $\mathrm{D}_{3}$ from these sources cannot provide sufficient vitamin $\mathrm{D}_{3}$ for the elderly (Mosekilde, 2005). Vitamin $\mathrm{D}_{3}$ can also be obtained through vitamin tablets; however the simplest way to obtain vitamin $\mathrm{D}_{3}$ is from moderate exposure to sunlight (Holick, 2004). Furthermore, this is also the cheapest way without the cost burden of vitamin tablets.

Current Australian guidelines suggest exposure to approximately $1 / 6$ to $1 / 3$ of a MED (minimum erythemal dose), depending on age, would be appropriate to provide adequate vitamin $\mathrm{D}_{3}$ levels (Samanek et al., 2006; CDHAA, 2004). Older people require more frequent exposures as vitamin $\mathrm{D}_{3}$ production rates are about $1 / 5$ as high for the elderly as for

Published by Copernicus Publications on behalf of the European Geosciences Union. 
the young (Holick et al., 1989). Also, people with highly pigmented skin would require exposures 3-4 times greater than those necessary for fair skinned people (Pathak et al., 1999). Recent research suggests that the optimal serum vitamin $\mathrm{D}_{3}$ level for bone health and protection against other diseases is between 800 and $2000 \mathrm{IU}$ per day (Aloia and $\mathrm{Li}-\mathrm{Ng}, 2007$; Lappe et al., 2007; Vieth et al., 2007; Dawson-Hughes et al., 2005); with 1000 IU equivalent to exposing $15 \%$ of the human body to approximately $1 / 3$ MED (PS, 2006). A position statement was recently approved by the Working Group of the Australian and New Zealand Bone and Mineral Society, Endocrine Society, Osteoporosis Australia, Australian College of Dermatologists and the Cancer Council Australia recommending five minutes solar UV exposure either side of the peak UV periods on most days of the week in summer and approximately $2-3 \mathrm{~h}$ solar UV exposure over a week in winter (PS, 2006). This position statement is still behind emerging scientific findings (e.g. Giovannucci et al., 2006; Grant et al., 2007; Gorham et al., 2007; Garland et al., 2007). Nevertheless, it is still the most up to date statement that has been distributed to the public. The position statement is also a generalized report as sun exposure varies significantly with latitude and atmospheric conditions.

Solar UV radiation is incident on the earth's surface in two distinct components, direct and diffuse. The direct component is straight forward to minimise by simply blocking its path, whereas the diffuse component is incident from all directions and is difficult to minimise. Atmospheric scattering which is influenced by factors such as solar zenith angle (SZA), clouds and atmospheric constituents plays a major role in determining the proportions of UVB $(280-315 \mathrm{~nm})$ and UVA (315-400 nm) in diffuse UV, with greater scattering occurring at the shorter UVB wavelengths than at the longer wavelength UVA. Turnbull et al. (2005) found that UVA was reduced by as much as $65 \%$ when utilising a shade umbrella, whereas UVB exposures were only reduced by approximately $48 \%$. Therefore, at certain SZA, the diffuse UV may provide adequate levels of the effective wavelengths needed for vitamin $\mathrm{D}_{3}$ production $\left(\mathrm{UV}_{\mathrm{D}_{3}}\right)$, without producing erythema. In comparison, mutagenic and carcinogenic effects on human skin have been shown to be caused by exposure to UVA radiation (Agar et al., 2004; Moan et al., 1999; Garland et al., 2003). Therefore, reducing personal exposures to UVA radiation while still receiving sufficient amounts of the $\mathrm{UV}_{\mathrm{D}_{3}}$ wavelengths required to produce recommended vitamin $\mathrm{D}_{3}$ levels is essential.

The importance of this research is that it provides a basis for public health campaigns aimed at reducing the incidence of hypovitaminosis D and its attendant disorders, as well as reducing over exposure to harmful solar UV radiation. In the light of the considerable body of evidence regarding the harm done by excessive UV exposure and the public awareness of skin cancer, any new public health program would need to avoid confusing the public with seemingly opposing messages. Utilizing diffuse solar UV radiation to obtain beneficial amounts of UV, while at the same time minimizing personal overexposure to UVA radiation may prove to be absolutely necessary for an improvement in public health. Studies have shown that shade structures are important as a UV minimisation strategy; however, shade settings may also play an important role in providing exposures to the human body with adequate levels of UV radiation for vitamin $\mathrm{D}_{3}$ production without experiencing the higher levels of UVA experienced in full sun. The lengths of exposure to solar UV at noon in major Australian cities to produce exposures of $1 / 3$ and 1/6 MED has previously been reported (Samanek et al., 2006). Shade as a protective device has been discussed numerous times before (e.g. Turnbull and Parisi, 2006) and it is not the aim of this paper. This current paper is about the exposures that humans may receive when utilising solar UV for vitamin $\mathrm{D}_{3}$ synthesis and the possible methods to optimise this radiation. The author's are unaware of any similar research or attempts to show how solar UV exposures can be optimised so humans can receive adequate vitamin $\mathrm{D}_{3}$ levels as well as reducing their total UV exposure.

\section{Materials and methods}

\subsection{Integrated automated cloud and spectral UV measure- ment system}

An integrated automated cloud and spectral UV measurement system was employed at a Southern Hemisphere site at Toowoomba, Australia $\left(27.6^{\circ} \mathrm{S}, 151.9^{\circ} \mathrm{E}, 693 \mathrm{~m}\right.$ above sea level) for automatically measuring every five minutes both the cloud fraction and the UV spectrum. The system was located on the roof of a building with relatively unobstructed views and the surrounding topography does not provide any significant obstruction to the field of view of the instruments.

The cloud detection system is a Total Sky Imager (TSI) (model TSI-440, Yankee Environmental Systems, MA, USA) with approximately $160^{\circ}$ field of view of the sky. The TSI consists of a CCD camera suspended over a hemispherical reflective dome that points upwards on a horizontal plane. For each image, digital analysis provides the fraction of cloud cover as a number between 0 and 1 where 1 represents total cloud cover. The uncertainty in the determination of the amount of cloud has been reported as $\pm 10 \%$ at least 95\% of the time (Sabburg and Long, 2004).

The spectral UV measurement system is located within three metres of the cloud detection system and is housed in an environmentally sealed box with a fibre optic connecting the diffuser to the input slit of the monochromator through a hole with a seal around the fibre to protect the equipment inside the box from the environment. The system is based on a double monochromator system model (DTM300, Bentham Instruments, Reading, UK) with the gratings having 2400 grooves $/ \mathrm{mm}$. The input and output slit widths on the monochromator of $0.37 \mathrm{~mm}$ have been selected to provide a 
bandwidth of $0.5 \mathrm{~nm}$. The spectral UV data was recorded from 280 to $400 \mathrm{~nm}$ in $0.5 \mathrm{~nm}$ increments. The input optics are provided by a diffuser (model D6) with the manufacturer determined error associated with the cosine response as less than $\pm 0.8 \%$ for a SZA up to $70^{\circ}$ and $\pm 3.3 \%$ for an SZA of $80^{\circ}$. The system is scheduled to scan every five minutes from 05:00EST (Eastern Standard Time) to 17:00 EST and the start of the initialisation of a spectral scan is one minute before the TSI obtains an image of the sky. This allows the spectral scan to start at approximately the same time that the TSI takes the sky image. Wavelength and irradiance calibration of the spectral UV system was undertaken by employing the $365 \mathrm{~nm}$ mercury spectral line and a 150 Watt quartz halogen lamp with calibration traceable to the National Physical Laboratory, UK standard.

\subsection{Diffuse and global erythemal UV}

Two erythemal UV meters (UV-Biometer Model 501, Solar Light Co., Philadelphia, PA. USA) were employed to monitor the diffuse and global erythemal UV ( $\left.U_{\text {ery }}\right)$. The diffuse $\mathrm{UV}_{\text {ery }}$ meter is a global $\mathrm{UV}_{\text {ery }}$ meter that has been specifically set up to measure the diffuse erythemal radiation. It utilizes a shadow band, which is aligned east-west, to block the sun during the day. The shadow band is $0.076 \mathrm{~m}$ wide and the distance from the shadow band to the top of the diffuse $\mathrm{UV}_{\text {ery }}$ meter varies from $0.25 \mathrm{~m}$ to $0.27 \mathrm{~m}$ as it is moved with the seasons. The shadow band blocks out part of the sky view and the amount blocked has been measured at approximately $10 \%$. A correction has been applied to all of the data to account for this. The diffuse and global $\mathrm{UV}_{\text {ery }}$ meters were set up to record data every five minutes. The meters are temperature stabilized to $25^{\circ} \mathrm{C}$ and calibrated twice a year during clear sky conditions against the scanning spectroradiometer. The daily atmospheric column of ozone as obtained from the TOMS (Total Ozone Mapping Spectrometer) ranged from 243.5 to $337.0 \mathrm{DU}$ and the SZA ranged from $4^{\circ}$ to $80^{\circ}$ over the twelve month measurement period from January to December 2003.

\section{Results}

\subsection{Diffuse and global erythemal UV}

An example of diffuse and global UV spectra is shown in Fig. 1a for a cloud free period on 17 August 2005 at 11:55 EST for an SZA of $40^{\circ}$. This illustrates the variation in the relative proportions of the different wavelengths when comparing diffuse UV to global UV. For Fig. 1a, the diffuse spectral irradiance summed over the UVA waveband was $16.8 \mathrm{~W} / \mathrm{m}^{2}$ compared to $44.5 \mathrm{~W} / \mathrm{m}^{2}$ for the global UVA. Similarly, the diffuse UVB was $0.63 \mathrm{~W} / \mathrm{m}^{2}$ compared to $1.12 \mathrm{~W} / \mathrm{m}^{2}$ for global UVB. For this specific date and time, the UVA was reduced by approximately $62 \%$ compared to the global UVA, whereas the diffuse UVB was only reduced (a)

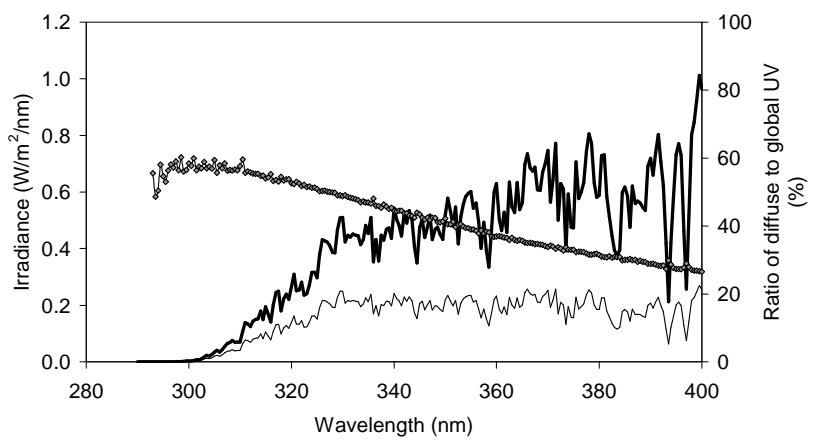

(b)

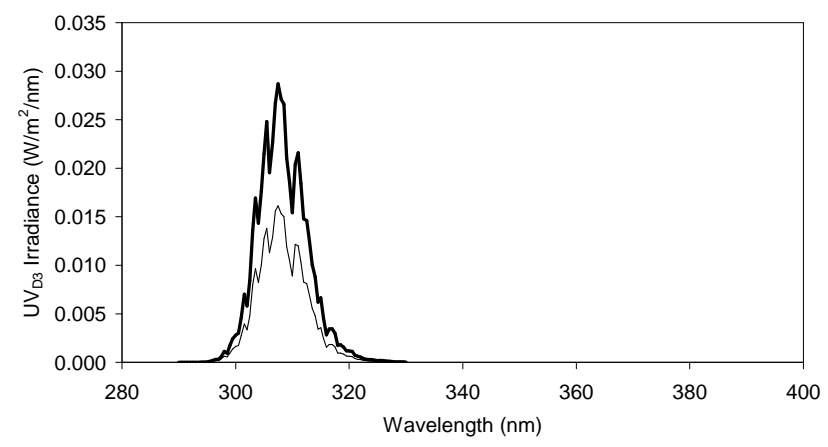

Fig. 1. Diffuse (light line) and global (heavy line) spectral UV irradiances taken on 17 August 2005 at approximately 11:00 EST and the spectral ratio of diffuse to global UV (a); and global and diffuse spectral irradiances from Fig. 1a weighted with the pre-vitamin $\mathrm{D}_{3}$ action spectrum (CIE, 2006) (b).

by approximately $44 \%$. The ratio of the diffuse to global UV plotted on the right hand axis of Fig. 1b gives an indication of the change in ratio when comparing global and diffuse UV wavelengths.

Figure $1 \mathrm{~b}$ provides the global and diffuse solar UV spectra (from Fig. 1a) weighted with the pre-vitamin D (CIE, 2006) action spectrum. Pre-vitamin $\mathrm{D}_{3}$ exposure was reduced by $43 \%$ whereas UVA exposure was reduced by $64 \%$. These spectral measurements were obtained using the spectral measurement system described earlier.

\subsection{Exposure times for $1 / 3 \mathrm{MED}$}

The times required for an exposure of 1/3 MED on a horizontal plane for SZA greater than $4^{\circ}$ for the atmospheric and cloud conditions during 2003 are shown in Fig. 3a for diffuse and Fig. $3 b$ for global $U_{\text {ery }}$. Over 25000 data points are provided in each figure for diffuse and global $\mathrm{UV}_{\text {ery }}$ for all SZA, sky and atmospheric conditions encountered over this period. The average times for an exposure equivalent to $1 / 3$ MED for vitamin $D_{3}$ and erythema are shown in Table 1 for diffuse and global UV. For a SZA of $5^{\circ}$, the average time needed to receive an exposure of $1 / 3$ MED due to erythemal 
Table 1. Average times for an exposure equivalent to $1 / 3$ MED for vitamin $D_{3}$ and erythemal effective UV radiation.

\begin{tabular}{ccccc}
\hline & Global UVD $_{3}$ & Diffuse $\mathrm{UVD}_{3}$ & Global UV ery & Diffuse UV ery \\
\hline $\mathrm{SZA}$ & $(\min )$ & $(\min )$ & $(\min )$ & $(\min )$ \\
\hline $5^{\circ}$ & $2.2(0.8)$ & $3.2(0.5)$ & $4.4(2.5)$ & $6.8(2.8)$ \\
$15^{\circ}$ & $2.5(3.4)$ & $3.9(3.1)$ & $5.1(5.9)$ & $7.7(5.2)$ \\
$25^{\circ}$ & $2.8(1.8)$ & $4.5(2.6)$ & $6.0(4.5)$ & $8.7(4.0)$ \\
$35^{\circ}$ & $3.5(2.0)$ & $5.2(2.5)$ & $7.1(4.2)$ & $10.2(4.3)$ \\
$45^{\circ}$ & $5.7(3.8)$ & $7.1(3.1)$ & $10.8(6.6)$ & $13.7(5.4)$ \\
$55^{\circ}$ & $10.1(5.9)$ & $13.2(7.7)$ & $19.9(16.5)$ & $24.2(16.3)$ \\
$65^{\circ}$ & $27.5(19.0)$ & $27.2(17.2)$ & $42.0(30.8)$ & $43.6(25.1)$ \\
$75^{\circ}$ & $103.3(63.5)$ & $97.7(47.7)$ & $110.3(56.3)$ & $111.6(49.3)$ \\
\hline
\end{tabular}

(a)

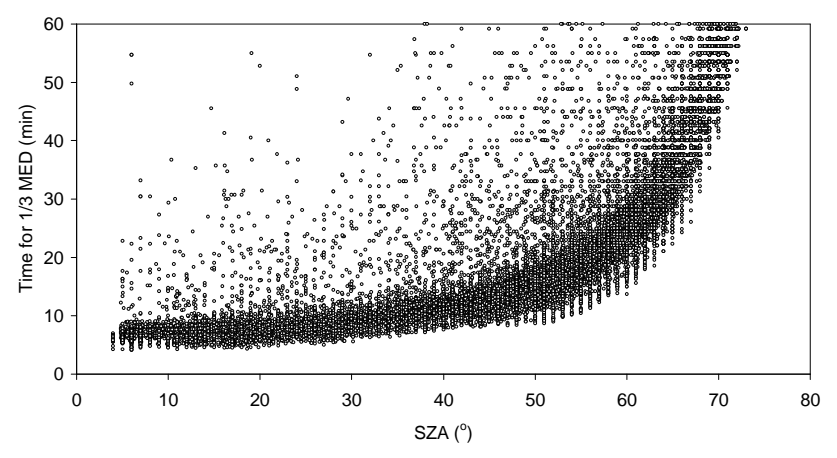

(b)

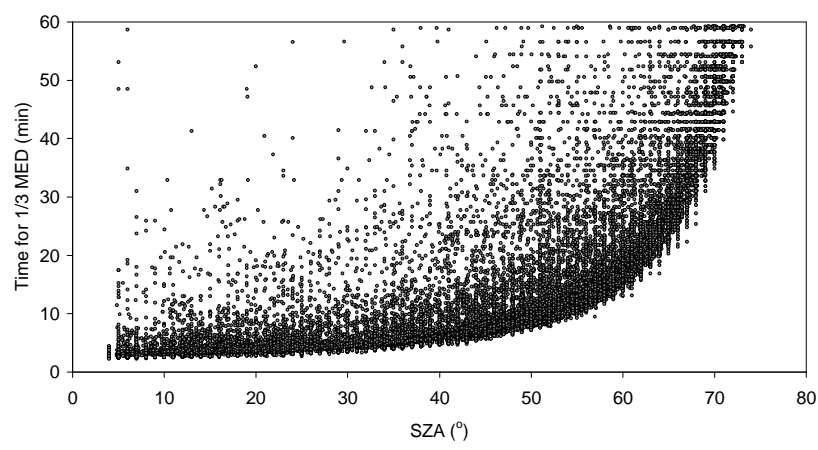

Fig. 2. The times required for an exposure of $1 / 3$ MED due to diffuse $\mathrm{UV}_{\text {ery }}$ (a) and global $\mathrm{UV}_{\text {ery }}$ (b) as a function of SZA for all sky conditions during 2003.

UV was 4.4 and $6.8 \mathrm{~min}$ for global and diffuse respectively. Whereas, the average time needed to receive an equivalent exposure of $1 / 3 \mathrm{MED}$ for vitamin $\mathrm{D}_{3}$ production was 2.2 and $3.2 \mathrm{~min}$ for global and diffuse respectively. These times are based on exposing $15 \%$ of the human body to UV radiation. Increasing the exposed body surface will subsequently decrease the time needed for vitamin $\mathrm{D}_{3}$ production (e.g. exposing three times more body surface will reduce the exposure times presented in this research by a factor of three). (a)

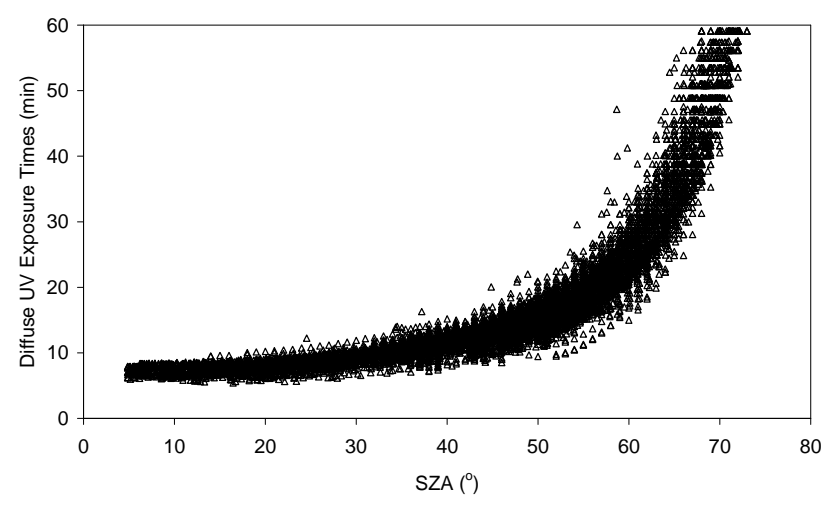

(b)

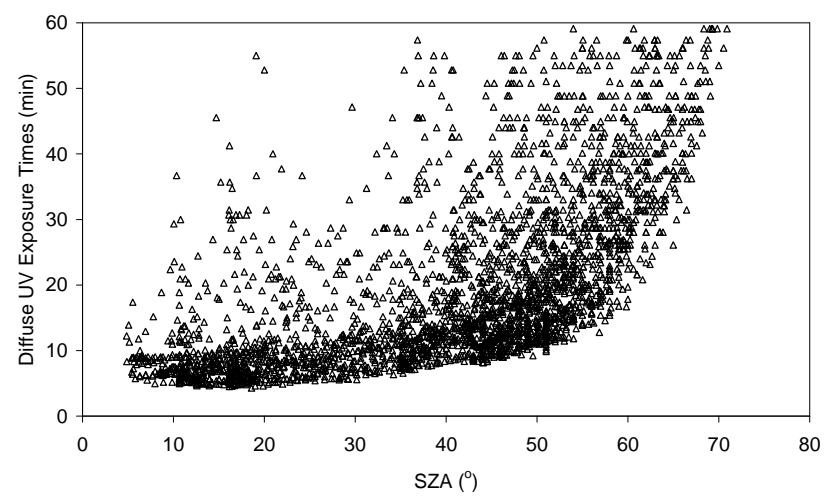

Fig. 3. Times for exposure to $1 / 3 \mathrm{MED}$ of diffuse UV for cloud cover of 0 to $80 \%$ (a) and 85 to $100 \%$ (b).

However, the time for $1 / 3 \mathrm{MED}$ of erythemal effective UV will remain the same.

As shown in Fig. 3a and b, this data has been broken down into separate cloud levels of 0 to $80 \%$ and 85 to $100 \%$, respectively. This was undertaken to illustrate that 0 to $80 \%$ of cloud cover has a lesser effect on the diffuse UV compared to 85 to $100 \%$ of cloud. 
The times required for an exposure of $1 / 3$ MED due to the diffuse and global $U_{\text {ery }}$ on a horizontal plane expressed as a percentage of occurrence for 2003 are shown in Fig. 4. For diffuse $\mathrm{UV}_{\text {ery }}$, the maximum incidence for $1 / 3$ MED was in the range of 5 to $10 \mathrm{~min}$ with an occurrence of $34.9 \%$, followed by $29.5 \%$ for 10 to $15 \mathrm{~min}$, and $17.8 \%$ for 15 to $20 \mathrm{~min}$. For global $\mathrm{UV}_{\text {ery }}$, the maximum incidence of the times for $1 / 3$ MED was in the range of 5 to $10 \mathrm{~min}$ with an occurrence of $32.9 \%$, followed by $26.7 \%$ for less than or equal to $5 \mathrm{~min}$, and $17.9 \%$ for 10 to $15 \mathrm{~min}$.

\section{Discussion}

Studies on the levels of UV observed in the shade of different shade environments have shown that the relative proportions of UVA and UVB in the shade are significantly different to those in full sun (Turnbull et al., 2005; Turnbull and Parisi, 2003; Turnbull et al., 2003; Parisi et al., 2001). The relative proportions of the UVA in shade to those in full sun are decreased compared to the relative proportions of the UVB in shade to those in full sun. At certain latitudes and SZA, unprotected exposure for short periods to the UV under shade structures may be the best course of action as it will contribute more toward vitamin $\mathrm{D}_{3}$ production than toward erythema compared to exposing the body to full sun UV due to the reduced relative component of the UVA in the shade.

The average time for an exposure of $1 / 3$ MED due to diffuse $\mathrm{UV}_{\text {ery }}$ was $6.8 \mathrm{~min}$ for a SZA of $5^{\circ}$. Whereas, the average time needed to receive an equivalent exposure of $1 / 3$ MED for vitamin $\mathrm{D}_{3}$ production was only $3.2 \mathrm{~min}$. These times are longer for larger SZA and for overcast conditions. For an exposure of $1 / 3$ MED, SZA smaller than approximately $50^{\circ}$ can be utilised for exposure times of less than $10 \mathrm{~min}$. For SZA between $4^{\circ}$ to $50^{\circ}, 94 \%$ of the data shows that an exposure of $1 / 3$ MED requires less than 20 min of exposure to diffuse UV. Although the measurements are at one latitude, the data was collected for the SZA range of $4^{\circ}$ to $80^{\circ}$. This will allow the results to be applicable at latitudes that experience these SZA.

The values provided in this paper are for pale skin and for a sky view that is not blocked, apart from the blocking of the solar disc. However, research is currently being conducted beneath various shade environments and initial results show that shade environments of at least 50\% sky view exhibit excellent correlation with the values shown in Fig. 2a. For example, at approximately $18^{\circ}$ SZA the average time for $1 / 3$ MED from diffuse $\mathrm{UV}_{\text {ery }}$ on a horizontal plane is approximately $7.5 \mathrm{~min}$. Initial results for the same SZA show that the times for 1/3 MED in the shade of a shade umbrella and on the southern side of a building were approximately $7 \mathrm{~min}$ and 9 min respectively. For larger structures the amount of sky view will be reduced due to the structural components of the shade structure, causing the exposure times required for the respective exposures due to the diffuse $U_{\text {ery }}$ to be

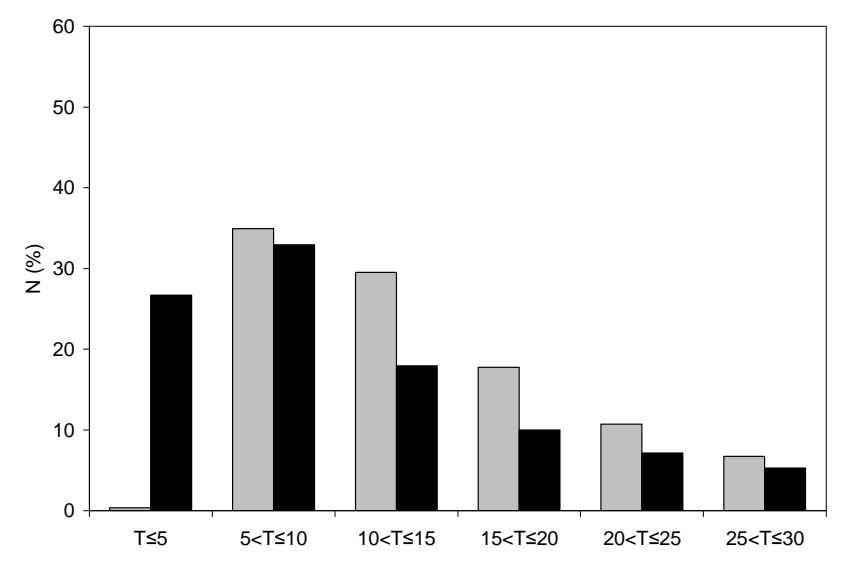

Fig. 4. The percentage of instances when the time required for an exposure of 1/3 MED due to diffuse (grey bar) and global (black bar) $\mathrm{UV}_{\text {ery }}$ falls within a certain time range (provided in units of minutes).

slightly longer. Nevertheless, the findings in this paper may have significant ramifications for future public health policy regarding sun exposure, which is currently being debated in many countries (Diffey, 2006; Gillie, 2006). Also, the findings of this research may prove useful to those that work from 9 a.m. to 5 p.m., where solar UV exposure at noon or during a lunch break may be the only option for the necessary UV exposures to initiate the synthesis of vitamin $\mathrm{D}_{3}$. Therefore, advice to stay out of the sun in the middle of the day, which is best for vitamin $D_{3}$ synthesis in the skin, can be adjusted to advocate the possible use of appropriate shade environments. However, in the shade there is the potential danger due to the filtering of the infrared waveband, which may cause prolonged exposures.

Acknowledgements. This research was supported by a Project Grant awarded by The Cancer Council Queensland.

Edited by: J. Groebner

\section{References}

Agar, N. S., Halliday, G. M., Barnetson, R. S., Ananthaswamy, H. N., Wheeler, M., and Jones, A. M.: The basal layer in human squamous tumors harbors more UVA than UVB fingerprint mutations: a role for UVA in human skin carcinogenesis, Proc. Nat. Acad. Sci., 101, 4954-4959, 2004.

Aloia, J. F. and Li-Ng, M.: Correspondence, Epidemiol. Infect., 135, 1095-1098, 2007.

Baron, E. A., Fourtanier, A., Compan, D., Medaisko, C., Cooper, K. D., and Stevens, S. R.: High ultraviolet A protection affords greater immune protection confirming that ultraviolet A contributes to photoimmunosuppression in humans, J. Invest. Derm., 121, 869-875, 2003.

CDHAA, Commonwealth Department of Health and Ageing Australia, Ministry of Health New Zealand and National Health 
and Medical Research Council: Nutrient reference values for Australia and New Zealand including recommended dietary intakes, Draft 2004, available at: http://www.moh.govt.nz/ moh.nsf/0/CC515A13536B3CB4CC256F6D000ABDE0/\$File/ nutrientreferencevalues.pdf, last access: 2 February 2006.

CIE (International Commission on Illumination): Action spectrum for the production of previtamin $\mathrm{D}_{3}$ in human skin, CIE, 174, 2006.

Dawson-Hughes, B., Heaney, R. P., Holick, M. F., Lips, P., Meunier, P. J., and Vieth, R.: Estimates of optimal vitamin D status, Osteoporos. Int., 16, 713-716, 2005.

Diffey, B.: Do we need a revised public health policy on sun exposure?, Brit. J. Dermatol., 154, 1046-1051, 2006.

Garland, C. F., Garland, F. C., and Gorham, E. D.: Epidemiologic evidence for different roles of ultraviolet $\mathrm{A}$ and $\mathrm{B}$ radiation in melanoma mortality rates, Ann. Epidemiol., 13, 395-404, 2003.

Garland, C. F., Gorham, E. D., Mohr, S. B., Grant, W. B., Giovannucci, E. L., Lipkin, M., Newmark, H., Holick, M. F., and Garland, F. C.: Vitamin D and prevention of breast cancer: Pooled analysis, J. Steroid. Biochem. Mol. Biol., 103, 708-711, 2007.

Gillie, O.: A new government policy is needed for sunlight and vitamin D, Brit. J. Dermatol., 154, 1052-1061, 2006.

Giovannucci, E., Liu, Y., Rimm, E. B., Hollis, B. W., Fuchs, C. S., Stampfer, M. J., and Willett, W. H.: Prospective study of predictors of vitamin D status and cancer incidence and mortality in men, J. Nat. Cancer Inst., 98, 451-459, 2006.

Glerup, H., Mikkelsen, L., Hass, E., Overbeck, S., Thomsen, J., Charles, P., and Eriksen, E. F.: Commonly recommended daily intake of vitamin D is not sufficient if sunlight exposure is limited, J. Intern. Med., 247, 260-268, 2000.

Gorham, E. D., Garland, C. F., Garland, F. C., Grant, W. B., Mohr, S. B., Lipkin, M., Newmark, H. L., Giovannucci, E., Wei, M., and Holick, M. F.: Optimal vitamin d status for colorectal cancer prevention a quantitative meta analysis, Am. J. Prev. Med., 32, 210-216, 2007.

Grant, W. B., Garland, C. F., and Gorham, E. D.: An estimate of cancer mortality rate reductions in Europe and the U.S. with 1000 I.U. of oral vitamin D per day, Rec. Results. Cancer. Res., 174, 225-234, 2007.

Holick, M. F., Matsuoka, L. Y., and Wortsman, J.: Age, vitamin D, and solar ultraviolet, Lancet, 2, 1104-1105, 1989.

Holick, M. F.: Evolution, biologic functions, and recommended dietary allowances for vitamin D, in: Vitamin D: Physiology, Molecular Biology and Clinical Applications, Humana Press, New Jersey, 1-16, 1998.

Holick, M. F.: Sunlight and vitamin D for bone health and prevention of autoimmune diseases, cancers, and cardiovascular disease, Am. J. Clin. Nutr., 80, 1678S-1688S, 2004.

Lappe, J. M., Travers-Gustafson, D., Davies, K. M., Recker, R. R., and Heaney, R. P.: Vitamin D and calcium supplementation reduces cancer risk: results of a randomized trial, Am. J. Clin. Nutr., 85, 1586-1591, 2007.

Lucas, R., McMichael, T., Smith, W., and Armstrong, B.: Solar ultraviolet radiation: global burden of disease from solar ultraviolet radiation, World Health Organization, Switzerland, 250 pp., 2006.
Moan, J., Dahlback, A., and Setlow, R. B.: Epidemiological support for an hypothesis for melanoma induction indicating a role for UVA radiation, Photochem. Photobiol., 70, 243-247, 1999.

Mosekilde, L.: Vitamin D and the elderly, Clin. Endocrinol., 62, 265-281, 2005.

Parisi, A. V., Kimlin, M. G., and Turnbull, D.: Spectral shade ratios on horizontal and sun normal surfaces for single trees and relatively cloud free sky, J. Photochem. Photobiol. B Biol., 65, 151-156, 2001.

Pathak, M. A., Nghiem, P., and Fitzpatrick, T. B.: Acute and chronic effects of the sun, in: Fitzpatrick's dermatology in general medicine, McGraw-Hill, New York, 1598-1607, 1999.

PS (Position Statement): Estimates of beneficial and harmful sun exposure times during the year for major Australian population centres, Med. J. Aust., 184, 338-341, 2006.

Sabburg, J. and Long, C. N.: Improved sky imaging for studies of enhanced UV irradiance, Atmos. Chem. Phys., 4, 2543-2552, 2004 , http://www.atmos-chem-phys.net/4/2543/2004/.

Samanek, A. J., Croager, E. J., Gies, P., Milne, E., Prince, R., McMichael, A. J., Lucas, R. M., and Slevin, T.: Estimates of beneficial and harmful sun exposure times during the year for major Australian population cities, Med. J. Aust., 184, 338-341, 2006.

Setlow, R. B., Grist, E., Thompson, K., and Woodhead, A. V.: Wavelengths in the induction of malignant melanoma, Proc. Nat. Acad. Sci., 90, 6666-6670, 1993.

Sliney, D. H.: Epidemiological studies of sunlight and cataract: the critical factor of ultraviolet exposure geometry, Ophthalmic Epidemiol., 1, 107-119, 1994.

Terenetskaya, I.: Spectral monitoring of biologically active solar UVB radiation using an in vitro model of vitamin D synthesis, Talanta, 53, 195-203, 2000.

Turnbull, D. J. and Parisi, A. V.: Spectral UV in Public Shade Settings, J. Photochem. Photobiol. B Biol., 69, 13-19, 2003.

Turnbull, D. J., Parisi, A. V., and Kimlin, M. G.: Vitamin D effective wavelengths due to scattered UV in the shade, J. Ster. Biochem. Mol. Biol., 96, 431-436, 2005.

Turnbull, D. J., Parisi, A. V., and Sabburg, J.: Scattered UV beneath public shade structures during winter, Photochem. Photobiol., 78, 180-183, 2003.

Turnbull, D. J. and Parisi, A. V.: Effective Shade Structures, Med. J. Aust., 184, 13-15, 2006.

Vieth, R., Bischoff-Ferrari, H., Boucher, B. J., Dawson-Hughes, B., Garland, C. F., Heaney, R. P., Holick, M. F., Hollis, B. W., Lamberg-Allardt, C., McGrath, J. J., Norman, A. W., Scragg, R., Whiting, S. J., Willett, W. C., and Zittermann, A.: The urgent need to recommend an intake of vitamin D that is effective, Am. J. Clin. Nutr., 85, 649-650, 2007.

Webb, A. R.: Vitamin D synthesis under changing UV spectra, in: Environmental UV Photobiology, Plenum Press, New York, 185-202, 1993. 